\title{
BMJ Open Socioeconomic deprivation, age and language are barriers to accessing personal health records: a cross-sectional study of a large hospital-based personal health record system
}

\author{
Rachel Chapman, ${ }^{1}$ Shamil Haroon (D) , ${ }^{1}$ Nikita Simms-Williams (D) , ${ }^{1}$ \\ Neeraj Bhala, ${ }^{1,2}$ Foyzal Miah, ${ }^{2}$ Krishnarajah Nirantharakumar, ${ }^{1}$ James Ferguson ${ }^{2,3}$
}

To cite: Chapman $\mathrm{R}$, Haroon $\mathrm{S}$, Simms-Williams N, et al. Socioeconomic deprivation, age and language are barriers to accessing personal health records: a cross-sectional study of a large hospitalbased personal health record system. BMJ Open 2022;12:e054655. doi:10.1136/ bmjopen-2021-054655

- Prepublication history for this paper is available online To view these files, please visit the journal online (http://dx.doi org/10.1136/bmjopen-2021054655).

Received 23 June 2021 Accepted 20 December 2021

D Check for updates

(C) Author(s) (or their employer(s)) 2022. Re-use permitted under CC BY-NC. No commercial re-use. See rights and permissions. Published by BMJ.

${ }^{1}$ University of Birmingham Institute of Applied Health Research, Birmingham, UK ${ }^{2}$ Medicine, University Hospitals Birmingham NHS Foundation Trust, Birmingham, UK ${ }^{3}$ National Institute for Health Research, Birmingham, UK

Correspondence to Nikita Simms-Williams; n.simms-williams@bham.ac.uk

\section{ABSTRACT}

Objectives To investigate barriers to accessing a hospitalbased personal health record (PHR) system.

Design Retrospective cross-sectional study.

Setting This study was conducted in a large secondary and tertiary acute care trust in Birmingham, UK.

Participants Data were collected from 28637 patients who attended liver medicine, diabetes, renal medicine or endocrinology specialist outpatient clinics from 1 June 2017 to 31 May 2018.

Primary and secondary outcome measures The primary outcome measure was sign up to and activation of the PHR. The secondary outcomes were the use of the PHR, defined as the number of logons and frequency of access of specific PHR functions.

Results 8070 patients (28.2\%) were signed up to the PHR and 4286 patients (53.1\% of those signed up) went on to activate their PHR account. Patients aged 75 years and older were significantly less likely to be signed up (adjusted OR, aOR $0.40,95 \% \mathrm{Cl} 0.36$ to 0.44 ) or to activate (aOR 0.39, 0.32 to 0.47 ) their PHR than patients aged 35-54. Patients who did not need an interpreter were more likely to be signed up (aOR $1.63,95 \% \mathrm{Cl} 1.33$ to 1.99) and to activate (aOR $3.16,95 \% \mathrm{Cl} 1.96$ to 5.09 ) their PHR. Patients living in the least deprived areas were more than twice as likely to be signed up (aOR $2.31,95 \% \mathrm{Cl}$ 2.04 to 2.63), and were three times more likely to activate their PHR (aOR 2.99, 95\% Cl 2.40 to 3.71), than those in the most deprived.

Conclusion Socioeconomic deprivation, older age and non-English language were significant barriers to accessing a hospital-based PHR. Strategies are needed to account for these factors to ensure that PHRs do not widen health inequalities.

\section{INTRODUCTION}

A personal health record (PHR) is a secure, online store of information about a person's health, care and well-being that is managed by the individual, with information added by both the individual and their healthcare provider. ${ }^{2}$ PHRs aim to empower individuals

\section{Strengths and limitations of this study}

- This is the first UK study of a multispecialty hospitalbased personal health record.

- This study has a large population size.

- This study characterises both users and non-users of the personal health record system.

- This study is set in a single centre.

- Not all clinical specialities were recorded in the analysis.

and support self-management by enabling them to access parts of their health records and communicate with their clinical team. The development of PHRs is a key feature of digital health innovation in several countries. For example, healthcare policy in Sweden aims for all adults to have access to full electronic health records (EHRs) by $2020,{ }^{3}$ and Australia has implemented an 'opt-out' approach for access to PHRs. ${ }^{4}$ However, there are a number of important barriers to their implementation such as the electronic duplication of paper-based processes, lack of interoperability between systems and a lack of clear regulations and incentive structures. ${ }^{5}$

In the UK, PHRs are part of all four nations' digital strategies for the National Health Service (NHS) and are a key priority in the NHS Long-Term Plan to improve outcomes and increase efficiency. ${ }^{6-10}$ Much of the work to date has focused on development and use of PHR systems in primary care. Patients can now view parts of their GP health record including test results and some correspondence. ${ }^{2}$ However, there is currently no national PHR system for hospitals.

University Hospitals Birmingham NHS Foundation Trust (UHB) is at the forefront of the development of a PHR system for use in 
the acute care setting. ${ }^{11}$ The myHealth@QEHB PHR system has been developed and built in-house with patient and clinical input, and rolled out in hospitals across all outpatient specialties. It is a secure web-access system which allows patients to view their test results, planned appointments, correspondence, in-patient history and medications. Patients can also upload documents to share with their clinical teams and network with other patients.

Despite the drive to develop and implement PHRs, a review by the Royal College of Physicians in 2016 found that there is little information on who uses them and how they are used. ${ }^{12}$ There is currently little evidence on the equality of access to PHRs across sociodemographic groups in secondary and tertiary care in the UK or how PHRs are used in this setting, which is important to know to improve implementation as well as health equity. The objectives of this study were, therefore, to investigate whether sociodemographic factors are associated with access to a PHR in secondary and tertiary care. A secondary objective was to assess how PHRs are used by patients in this setting.

\section{METHODS}

This study is reported according to the Strengthening the Reporting of Observational Studies in Epidemiology guidelines for observational studies. ${ }^{13}$

\section{Study design and setting}

This was a retrospective cross-sectional study using routinely collected data from EHRs and PHRs at Queen Elizabeth Hospital Birmingham (part of UHB), which is the largest single site hospital in England. ${ }^{14}$ It provides secondary and tertiary care services for the West Midlands region and some UK-wide specialist services (such as transplantation surgery) and treats over 2.2 million people each year. ${ }^{15}$ Patients were not involved in this study but are co-producing the development and implementation of the hospital-based PHR known as myHealth@QEHB.

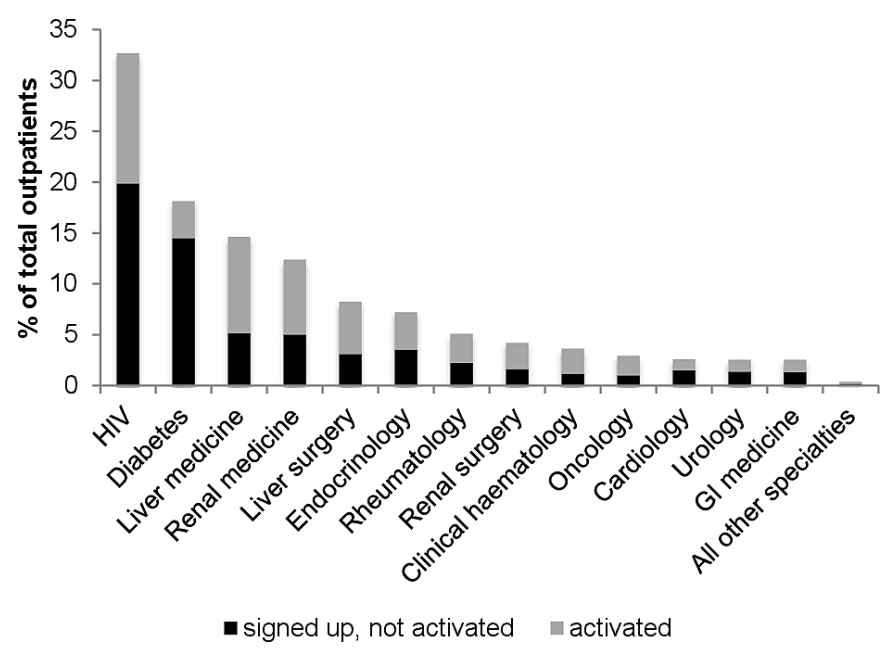

Figure 1 Proportion of patients who had been signed up and activated their PHR accounts by clinical specialty. PHR, personal health record.
Personal health record

MyHealth@QEHB has been available to patients in all clinical specialties within the hospital since 2012/2013. There is a two-step process to create and activate an account. First, patients attending outpatient clinics are offered access to the PHR by their healthcare professional. If a patient expresses an interest, their healthcare professional records this through the hospital clinical information system and the patient is 'signed up'. Second, patients receive a letter and must follow a verification process and register their details to activate their account. Accounts are then classed as 'activated'. While signing up involves the healthcare professional and the patient, activating the PHR account is patient-dependent.

\section{Population}

The study included all patients who had attended outpatient clinics since the incremental implementation of myHealth@QEHB during 2012/2013 to 13 March 2018. The main analyses were restricted to medical patients who attended liver medicine, diabetes, renal medicine and endocrinology outpatient clinics from 1 June 2017 to 31 May 2018, since these specialties had the largest uptake of PHRs in the hospital. Patients attending HIV outpatient clinics were excluded from the main analysis due to the increased sensitive nature of their data.

Patient and public involvement

No patients were involved.

\section{Data extraction}

Data on eligible patients were extracted from EHR and PHR databases. EHRs contained demographic and clinical data on all patients in the study population. Data were extracted on patients' age, sex, ethnicity, area of residence (at the level of the lower super output area, which is a geographical area covering a mean number of 1500 residents), interpreter requirement during appointments, the number of clinical specialties attended (used as a proxy indicator for multimorbidity) and the number of appointments attended from 1 June 2017 to 14 September 2018. Lower super output areas were converted to Index of Multiple Deprivation (IMD) deciles as measure of socioeconomic deprivation. ${ }^{16}$ IMD scores are area-based on multiple domains related to socioeconomic status such as income, employment and education. This was used as a proxy measure for socioeconomic status since individual level socioeconomic status data were not available in EHRs.

The PHR database held information on patients in the study population who had been signed up to myHealth@ QEHB. Data were extracted on the sign-up date, whether patients had activated their PHR account, the number of logons, logon dates, and the pages within the PHR that had been accessed from 1 June 2017 to 14 September 2018. A unique anonymised identifier was assigned to each patient prior to release for analysis. 
Table 1 Characteristics of the study population by personal health record use

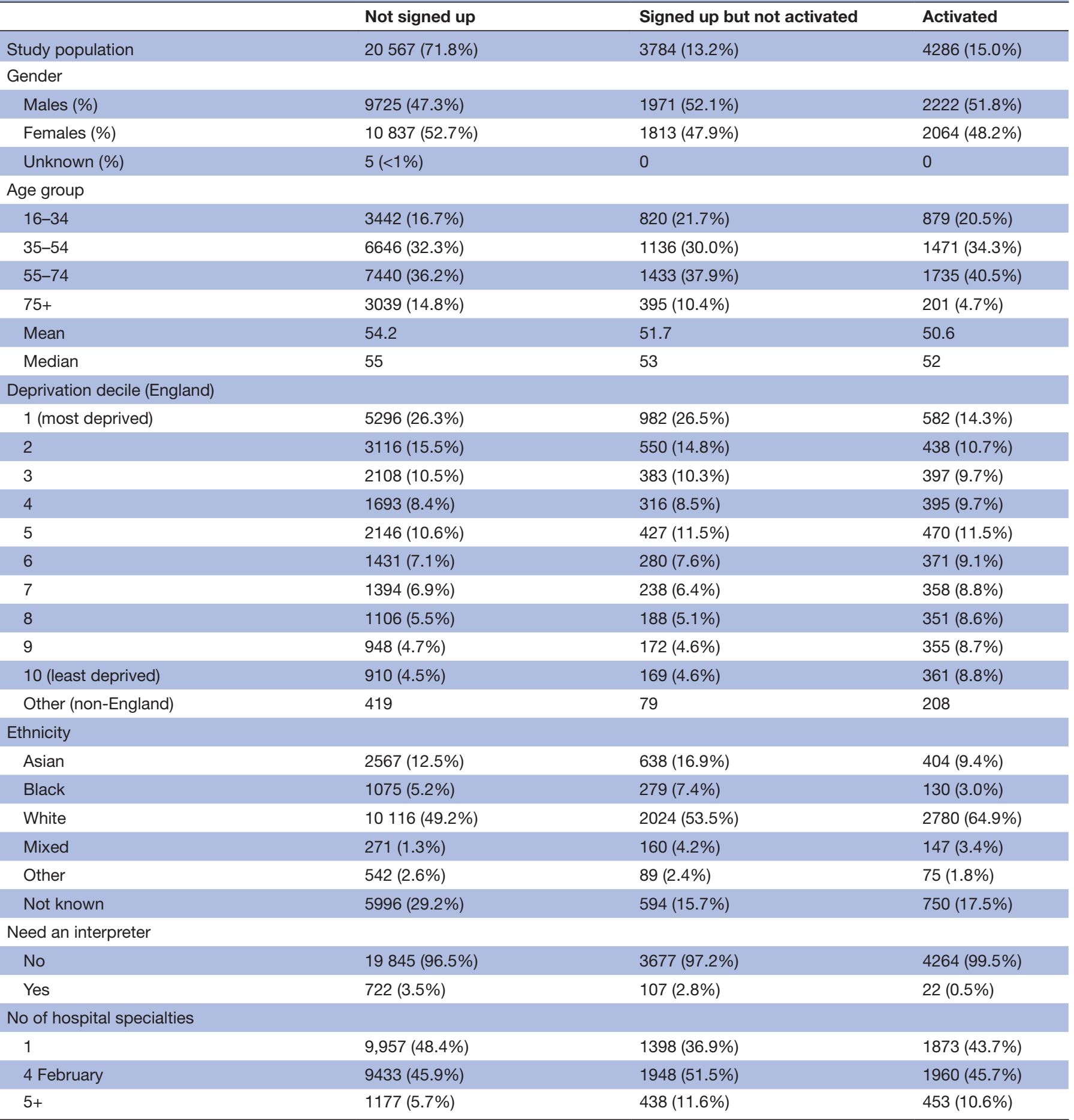

\section{Primary and secondary outcomes}

The primary outcomes were PHR sign up and activation. The secondary outcomes were the use of the PHR, defined as the number of logons and frequency of access of specific PHR functions.

\section{Statistical analysis}

The number and proportion of patients who signed up and activated the PHR were stratified by clinical specialty. Further analysis was limited to patients who attended liver medicine, diabetes, renal medicine and endocrinology clinics from 1 June 2017 to 31 May 2018. The unadjusted ORs for PHR sign up and activation were estimated for several patient factors to assess for variation by these characteristics. This was done by age group, sex, socioeconomic deprivation decile, ethnicity, requirement for an interpreter and number of clinical specialties attended. Separate multivariable logistic regression models were used to estimate adjusted OR (aOR). Model fit was assessed using the likelihood ratio $\chi^{2}$ test. A 


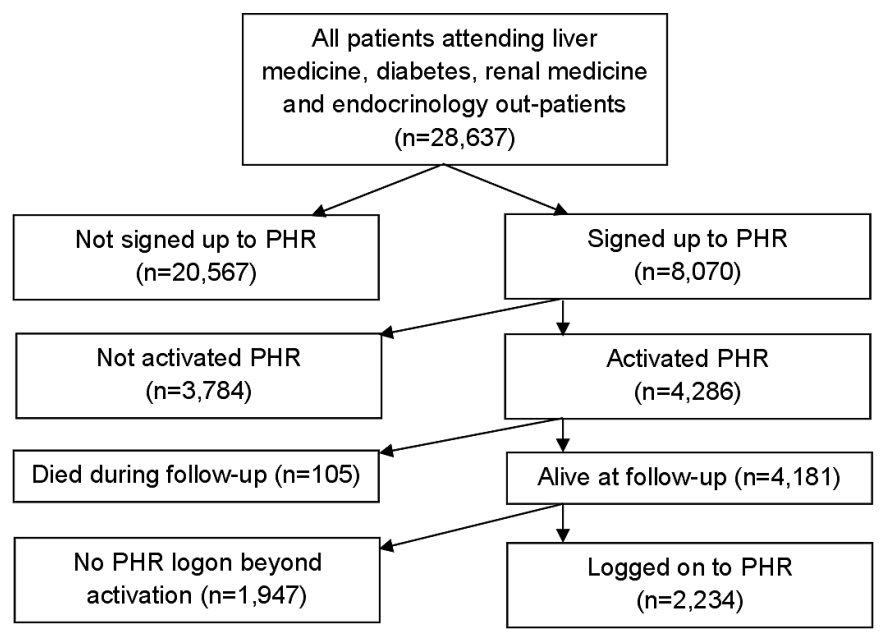

Figure 2 Participant flow diagram. PHR, personal health record.

complete-case analysis was performed due to the very low amount of missing data. Data were analysed using Stata SE V.15.1 and R V.3.5.1.

\section{RESULTS}

\section{PHR uptake}

From January 2012 to March 2018, 18859 patients had been signed up and 9776 patients had activated their PHR since its implementation across the hospital (out of 501090 total patients) (figure 1). Uptake varied across clinical specialties both in terms of sign up and activation. The highest uptake was from HIV, diabetes, liver medicine, renal medicine, liver surgery and endocrinology outpatient clinics. Across the four clinical specialties included in the main analysis $(\mathrm{n}=28637)$, 8070 patients (28.2\%) had signed up to the PHR and 4286 patients (53.1\% of those who had signed up) had activated their account.

\section{Characteristics of the study population}

A total of 28637 patients attended liver medicine, diabetes, renal medicine or endocrinology outpatient clinics from 1 June 2017 to 31 May 2018. Forty-eight per cent were male, the mean age was 53 years, and $52 \%$ were from a white ethnic group. Patients were categorised into three groups: those that had not been signed up to the PHR ( $\mathrm{n}=20567(71.8 \%))$, those that had been signed up but had not activated their account $(\mathrm{n}=3784(13.2 \%))$, and those that had activated their accounts $(n=4286$ $(15.0 \%))$. Table 1 summarises their characteristics. The flow of patients through the study is shown in figure 2 .

\section{Factors associated with PHR sign up}

A logistic regression model (table 2) showed that males were slightly more likely than females to be signed up (aOR $1.10,95 \%$ CI 1.04 to 1.16 ). Younger patients were also more likely to be signed up compared with older patients (aOR 1.47, 95\% CI 1.38 to 1.61 for under 35 years vs 35-54) with patients aged 75 and older being least likely to be signed up (aOR $0.40,95 \%$ CI 0.36 to 0.44 ).
There was significant variation in the likelihood of PHR sign up across the socioeconomic gradient. Table 2 and figure $3 \mathrm{~A}$ show that this increased as socioeconomic deprivation decreased, with those living in the most affluent decile being more than twice as likely (aOR 2.31, 95\% CI 2.04 to 2.63) to be signed up than those from the most deprived decile.

There were also some differences among ethnic groups, with patients from a mixed background being more likely than white patients to be signed up (aOR 2.62, 95\% CI 2.20 to 3.12) while patients from 'other' ethnic backgrounds were less likely (aOR $0.46,95 \%$ CI 0.43 to 0.49 ). However, the ethnic background was unknown for nearly $26 \%$ of the study population. There were also associations between the likelihood of sign-up and patients' fluency in English with those who did not need an interpreter being significantly more likely to be signed up than those who did need an interpreter (aOR 1.63, 95\% CI 1.33 to 1.99 ).

The largest association with PHR sign up however was seen with the number of clinical specialties, with those with five or more specialties being more than two and a half times more likely to be signed up than those with one specialty (aOR $2.54,95 \%$ CI 2.30 to 2.82 ).

\section{Factors associated with PHR activation}

In contrast to being signed up, males were less likely than females to activate their PHR (table 3: aOR 0.85, 95\% CI 0.78 to 0.94 ). Differences in the likelihood of PHR activation were also seen by age with patients aged $35-54$ being more likely than other age groups. While those aged 16-34 had been more likely to be signed up, they were less likely to activate their PHR compared with those aged 35-54 (aOR 0.80, 95\% CI 0.70 to 0.91). Again, those aged 75 and older were the least likely to do so (aOR $0.39,95 \%$ CI 0.32 to 0.47 ).

The pattern of increasing likelihood of sign up among patients from less deprived areas was also seen with the likelihood of PHR activation (table 3 and figure 3B), with those in the least deprived areas again being three times more likely to activate their accounts than those from the most deprived areas (aOR 2.99, 95\% CI 2.40 to 3.71).

Patients from Asian, black and mixed ethnic groups were all significantly less likely than those from White ethnic groups to activate their PHR accounts. Similarly, patients who did not need an interpreter were over three times more likely to activate their accounts than those who did need one (aOR 3.16, 95\% CI 1.96 to 5.09).

While patients who were registered with more than one clinical specialty were more likely to be signed up, there was no significant association between the number of specialties and the likelihood of activating the PHR.

\section{Ongoing use of the PHR}

Data on PHR use were available for 4181 patients who were alive at the end of the follow-up period (1 June 2017 to 14 September 2018) and had activated their accounts. Of these, $1947(46.6 \%)$ had not logged on beyond activating their account. The remaining 2234 patients (53.4\%) had logged 
Table 2 Logistic regression model assessing the association between the likelihood of sign up to the PHR and patient characteristics $(n=28637)$

\begin{tabular}{|c|c|c|c|c|}
\hline \multirow[b]{2}{*}{ Variable } & \multirow{2}{*}{$\begin{array}{l}\text { Unadjusted OR } \\
(95 \% \mathrm{Cl})\end{array}$} & \multirow[b]{2}{*}{$P$ value } & \multirow{2}{*}{$\begin{array}{l}\text { Adjusted OR* } \\
(95 \% \mathrm{Cl})\end{array}$} & \multirow[b]{2}{*}{$P$ value } \\
\hline & & & & \\
\hline \multicolumn{5}{|l|}{ Gender } \\
\hline \multicolumn{5}{|l|}{ Female (reference) } \\
\hline Males & 1.11 (1.06 to 1.17$)$ & $<0.001$ & $1.10(1.04$ to 1.16$)$ & $<0.001$ \\
\hline \multicolumn{5}{|l|}{ Age group } \\
\hline \multicolumn{5}{|l|}{ 35-54 (reference) } \\
\hline $16-34$ & 1.25 (1.17 to 1.35$)$ & $<0.001$ & 1.47 (1.38 to 1.61$)$ & $<0.001$ \\
\hline $55-74$ & $1.08(1.02$ to 1.15$)$ & 0.009 & 0.94 (0.88 to 1.00$)$ & 0.064 \\
\hline $75+$ & 0.50 (0.45 to 0.55$)$ & $<0.001$ & 0.40 (0.36 to 0.44$)$ & $<0.001$ \\
\hline \multicolumn{5}{|c|}{ Deprivation decile (England) } \\
\hline \multicolumn{5}{|l|}{1 (reference) } \\
\hline 2 & 1.07 (0.98 to 1.18$)$ & 0.126 & 1.10 (1.00 to 1.20$)$ & 0.054 \\
\hline 3 & 1.25 (1.13 to 1.38$)$ & $<0.001$ & 1.26 (1.14 to 1.40$)$ & $<0.001$ \\
\hline 4 & 1.42 (1.28 to 1.58$)$ & $<0.001$ & 1.46 (1.31 to 1.63$)$ & $<0.001$ \\
\hline 5 & 1.41 (1.28 to 1.56$)$ & $<0.001$ & 1.46 (1.32 to 1.61$)$ & $<0.001$ \\
\hline 6 & 1.54 (1.38 to 1.72$)$ & $<0.001$ & 1.67 (1.49 to 1.87$)$ & $<0.001$ \\
\hline 7 & 1.45 (1.30 to 1.62$)$ & $<0.001$ & 1.57 (1.40 to 1.77$)$ & $<0.001$ \\
\hline 8 & 1.65 (1.47 to 1.86$)$ & $<0.001$ & 1.87 (1.66 to 2.12 ) & $<0.001$ \\
\hline 9 & 1.88 (1.67 to 2.12 ) & $<0.001$ & 2.15 (1.90 to 2.44$)$ & $<0.001$ \\
\hline 10 least deprived & 1.97 (1.75 to 2.23$)$ & $<0.001$ & 2.31 (2.04 to 2.63 ) & $<0.001$ \\
\hline \multicolumn{5}{|l|}{ Ethnicity } \\
\hline \multicolumn{5}{|l|}{ White (reference) } \\
\hline Asian & 0.85 (0.79 to 0.93$)$ & $<0.001$ & 0.98 (0.90 to 1.06$)$ & 0.607 \\
\hline Black & 0.80 (0.71 to 0.90$)$ & $<0.001$ & 0.98 (0.86 to 1.11$)$ & 0.727 \\
\hline Mixed & 2.38 (2.02 to 2.81$)$ & $<0.001$ & 2.62 (2.20 to 3.12$)$ & $<0.001$ \\
\hline Other & 0.64 (0.53 to 0.76$)$ & $<0.001$ & 0.46 (0.43 to 0.49$)$ & 0.002 \\
\hline Not known & 0.47 (0.44 to 0.51$)$ & $<0.001$ & 0.75 (0.62 to 0.90$)$ & $<0.001$ \\
\hline \multicolumn{5}{|l|}{ Need an interpreter } \\
\hline \multicolumn{5}{|l|}{ Yes (reference) } \\
\hline No & 2.24 (1.85 to 2.71$)$ & $<0.001$ & 1.63 (1.33 to 1.99$)$ & $<0.001$ \\
\hline \multicolumn{5}{|c|}{ No of clinical specialties } \\
\hline \multicolumn{5}{|l|}{1 (reference) } \\
\hline $2-4$ & 1.26 (1.19 to 1.33$)$ & $<0.001$ & 1.32 (1.24 to 1.40$)$ & $<0.001$ \\
\hline $5+$ & 2.30 (2.09 to 2.54$)$ & $<0.001$ & 2.54 (2.30 to 2.82$)$ & $<0.001$ \\
\hline
\end{tabular}

${ }^{*}$ Adjusted for all the patient characteristics listed in the table.

on a total of 84219 times during the follow-up period, with a median of 10 logons per patient (IQR 3-35).

Table 4 shows the number of patients who had logged on and the median cumulative number of logons, stratified by the number of years from being signed up to the PHR. This shows that patients who use the PHR access the system around 10 times or more, and patients who activated their accounts up to 7 years ago were continuing to use it.

Among the included clinical specialities, $75 \%$ of total logons were within 2 weeks of a clinic appointment date.
Of these, $39 \%$ were from 14 days before and up to the day of appointment, and $61 \%$ were within 14 days after. Patients most frequently used the PHR to view clinical correspondence and test results (figure 4).

\section{DISCUSSION}

Principal findings

The majority of medical patients attending outpatient clinics in a large secondary and tertiary care centre had 
A. Likelihood of being signed up to the PHR by the Index of Multiple Deprivation decile ( $1=$ most socioeconomically deprived, $10=$ least socioeconomically deprived)

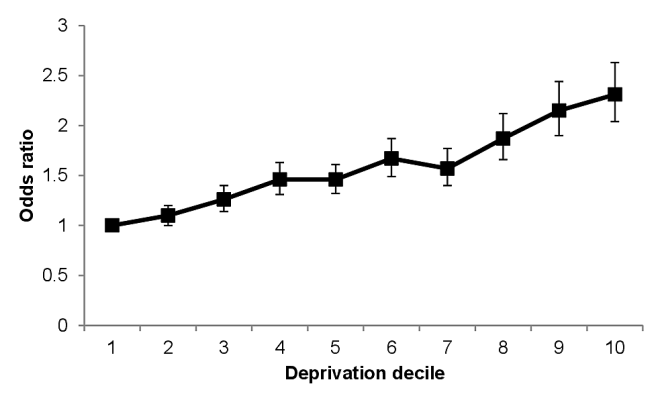

B. Likelihood of activating the PHR by the Index of Multiple Deprivation decile

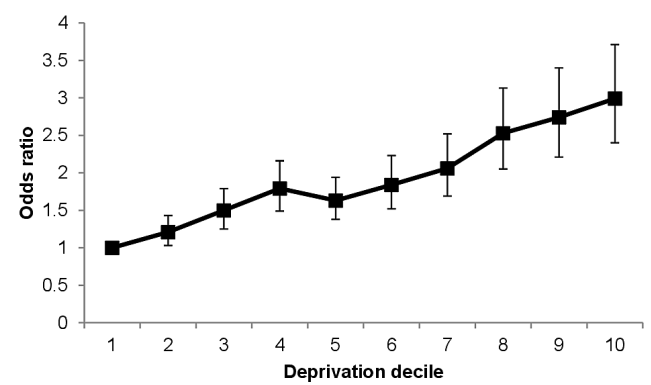

Figure 3 Relationship between socioeconomic status and sign-up or activation of the personal health record (PHR).

not been signed up to use a personal care record. Patients who lived in a socioeconomically deprived area, were over 75 years of age or did not speak English, were less likely to be signed up to or activate a PHR. Patients from nonwhite ethnic backgrounds were also less likely to activate a PHR after they had been signed up. Patients attending multiple clinical specialties were more likely to be signed up to use a PHR but those who attended only a single specialty were just as likely to activate their account once they had been signed up. Finally, patients were most likely to use their PHR within 2 weeks of their clinic visit and mostly to view clinical correspondence and test results.

\section{Strengths and limitations}

This study provides real world evidence on the use of a hospital-based PHR. It is the first large scale evaluation of the use of a multispecialty hospital-based PHR system in the UK, with analysis of over 28000 patients. MyHealth@ $Q E H B$ has been developed and built in-house by the NHS, enabling ongoing coproduction with patients and clinicians. The study has included a large population of patients and has been able to characterise both the users and non-users of the system.

A limitation of this study is that it is set in a single centre that provides services at a local, regional and supraregional level. However, it serves an ethnically and socially diverse population, so the results are likely to be generalisable to other areas of similar sociodemographic diversity.

Another weakness of the data is the incomplete recording of ethnicity. In addition, not all clinical specialties were included in the analysis due to low numbers of signed up patients, especially in surgical specialties. This likely reflects the longer-term follow-up of patients with chronic health conditions who are potentially more likely to benefit from access to a PHR.

Finally, the data from this study were derived from subspecialty care and may not be generalisable to a primary care setting. The findings should be interpreted in the context of a UK-based system in which patients are already able to view aspects of their primary care record, such as their prescriptions, on a smartphone app. However, access to personal health information related to subspecialty care in the UK remains highly restricted, with myHealth@QEHB being a relatively rare example of a platform that enables this across multiple secondary and tertiary care specialties. We anticipate that its use would be particularly relevant to patients with chronic conditions requiring recurrent access to subspecialty services, as evidenced by the type of clinic specialties with the highest uptake (HIV, diabetes and liver medicine). Due to the limits of our study sample size and available data, we were unable to control for clinic-level factors in our analyses.

\section{Comparison with other studies}

A recent review of PHRs concluded that demographic factors such as age, socioeconomic deprivation and ethnicity did not significantly affect sign up to or use of PHRs but that more work was needed to understand who was using them. ${ }^{12}$ However, very few studies in the review had looked at sociodemographic factors and those that had were usually small. In contrast, a study of the use of renal patient view (RPV), a UK-based PHR for patients with chronic kidney disease, found similarly to our study that patients aged under 35 or over 75 years, and those living in more socioeconomically deprived areas were less likely to access a PHR. ${ }^{17}$ Unlike myHealth@QEHB, RPV is designed for a specific chronic disease and is used in both primary and secondary care. The RPV study did not have access to data on non-users and so used all UK patients in receipt of renal replacement therapies as a comparator. However, this did not result in any significant differences to our findings.

Access to PHRs has been more extensively studied in primary care. A systematic review of PHRs in primary care found that online health records tended to be accessed by older or middle-aged individuals and females. ${ }^{18}$ Multimorbidity was associated with higher levels of access, which was similarly reflected in the greater sign up to myHealth@QEHB but not in subsequent activation of PHR accounts. Another systematic review of studies mainly in North America found that while many did not report the characteristics of patients who used PHRs, those with higher clinical need and higher levels of education were more likely to use them. ${ }^{19}$ The impact of age and gender were variable, but patients in ethnic minority groups were generally less likely to use PHRs. A national survey of PHR access in the USA found that not having a regular 
Table 3 Logistic regression model assessing the association between the likelihood of PHR activation and patient characteristics among those who had been signed up $(n=8070)$

\begin{tabular}{|c|c|c|c|c|}
\hline Variable & $\begin{array}{l}\text { Unadjusted OR } \\
(95 \% \mathrm{Cl})\end{array}$ & $P$ value & $\begin{array}{l}\text { Adjusted OR* } \\
(95 \% \mathrm{Cl})\end{array}$ & $P$ value \\
\hline \multicolumn{5}{|l|}{ Gender } \\
\hline \multicolumn{5}{|c|}{ Female (reference) } \\
\hline Males & 0.85 (0.78 to 0.93$)$ & $<0.001$ & 0.85 (0.78 to 0.94$)$ & 0.001 \\
\hline \multicolumn{5}{|l|}{ Age group } \\
\hline \multicolumn{5}{|c|}{ 35-54 (reference) } \\
\hline $16-34$ & 0.83 (0.73 to 0.94$)$ & 0.003 & $0.80(0.70$ to 0.91$)$ & 0.001 \\
\hline $55-74$ & 0.94 (0.84 to 1.04$)$ & 0.207 & 0.86 (0.77 to 0.96$)$ & 0.006 \\
\hline $75+$ & 0.39 (0.33 to 0.47$)$ & $<0.001$ & 0.39 (0.32 to 0.47$)$ & $<0.001$ \\
\hline \multicolumn{5}{|c|}{ Deprivation decile (England) } \\
\hline \multicolumn{5}{|l|}{1 (reference) } \\
\hline 2 & 1.34 (1.14 to 1.58$)$ & $<0.001$ & 1.21 (1.03 to 1.43$)$ & 0.022 \\
\hline 3 & 1.75 (1.47 to 2.08$)$ & $<0.001$ & 1.50 (1.25 to 1.79$)$ & $<0.001$ \\
\hline 4 & 2.11 (1.76 to 2.53 ) & $<0.001$ & 1.79 (1.49 to 2.16$)$ & $<0.001$ \\
\hline 5 & 1.86 (1.57 to 2.19$)$ & $<0.001$ & 1.63 (1.38 to 1.94$)$ & $<0.001$ \\
\hline 6 & 2.23 (1.86 to 2.69 ) & $<0.001$ & 1.84 (1.52 to 2.23$)$ & $<0.001$ \\
\hline 7 & 2.54 (2.09 to 3.08 ) & $<0.001$ & 2.06 (1.69 to 2.52$)$ & $<0.001$ \\
\hline 8 & 3.15 (2.57 to 3.87 ) & $<0.001$ & 2.53 (2.05 to 3.13$)$ & $<0.001$ \\
\hline 9 & 3.48 (2.83 to 4.29$)$ & $<0.001$ & 2.74 (2.21 to 3.40$)$ & $<0.001$ \\
\hline 10 & 3.60 (2.92 to 4.44$)$ & $<0.001$ & 2.99 (2.40 to 3.71$)$ & $<0.001$ \\
\hline \multicolumn{5}{|l|}{ Ethnicity } \\
\hline \multicolumn{5}{|c|}{ White (reference) } \\
\hline Asian & 0.46 (0.40 to 0.53$)$ & $<0.001$ & 0.61 (0.53 to 0.71$)$ & $<0.001$ \\
\hline Black & 0.34 (0.27 to 0.42$)$ & $<0.001$ & 0.45 (0.36 to 0.56$)$ & $<0.001$ \\
\hline Mixed & 0.67 (0.53 to 0.84$)$ & 0.001 & 0.77 (0.60 to 0.97 ) & 0.03 \\
\hline Other & 0.61 (0.45 to 0.84$)$ & 0.002 & 0.75 (0.54 to 1.05$)$ & 0.095 \\
\hline Not known & 0.92 (0.81 to 1.04$)$ & 0.176 & 0.88 (0.77 to 1.00$)$ & 0.061 \\
\hline \multicolumn{5}{|c|}{ Need interpreter } \\
\hline \multicolumn{5}{|c|}{ Yes (reference) } \\
\hline No & 5.64 (3.56 to 8.94$)$ & $<0.001$ & 3.16 (1.96 to 5.09$)$ & $<0.001$ \\
\hline \multicolumn{5}{|c|}{ Number of clinical specialties } \\
\hline \multicolumn{5}{|l|}{1 (reference) } \\
\hline $2-4$ & 0.75 (0.68 to 0.82$)$ & $<0.001$ & 0.88 (0.79 to 0.97$)$ & 0.012 \\
\hline $5+$ & 0.77 (0.66 to 0.90$)$ & 0.001 & 1.01 (0.86 to 1.18$)$ & 0.922 \\
\hline
\end{tabular}

${ }^{*}$ Adjusted for all the patient characteristics listed in the table.

PHR, personal health record.

primary care physician, lower educational attainment, having lower English proficiency and being male were associated with poorer access. ${ }^{20}$ However, the same survey showed that use of PHRs was generally uniform across demographic groups once access had been achieved. Another national survey in the USA found that a preference for in-person communication was one of the most prevalent barriers to PHR use. ${ }^{21}$ Patients did not perceive the need for PHRs in order to achieve effective communication. An observation study of PHR access in the US highlighted possible mechanisms for lower PHR use among outpatients from socioeconomically deprived backgrounds, including lower levels of digital health literacy and a lack of access to internet connectivity, resulting in a digital divide. ${ }^{22}$

Once patients had activated their accounts, the pattern of use of myHealth@QEHB was consistent with that found for RPV, with approximately half of patients going on to use them regularly over time. ${ }^{17}$ Similar to our findings, patients using RPV logged on before and after their 
Table 4 Frequency of use of the personal health record by number of years since sign-up

\begin{tabular}{llll}
\hline $\begin{array}{l}\text { No of years } \\
\text { since sign- } \\
\text { up }\end{array}$ & $\begin{array}{l}\text { No of } \\
\text { patients who } \\
\text { logged on }\end{array}$ & $\begin{array}{l}\text { \% of activated } \\
\text { patients who } \\
\text { logged on }\end{array}$ & $\begin{array}{l}\text { Median } \\
\text { cumulative } \\
\text { no of logins } \\
\text { per patient } \\
\text { (IQR) }\end{array}$ \\
\hline $0-1$ & 397 & $65.2 \%$ & $6(2-25)$ \\
\hline $1-2$ & 480 & $66.9 \%$ & $10(3-45)$ \\
\hline $2-3$ & 348 & $48.7 \%$ & $12(4-38)$ \\
\hline $3-4$ & 375 & $47.3 \%$ & $13(3-43)$ \\
\hline $4-5$ & 255 & $42.5 \%$ & $12(4-32)$ \\
\hline $5-6$ & 338 & $49.6 \%$ & $11(4-34)$ \\
\hline $6-7$ & 41 & $61.2 \%$ & $17(2-31)$ \\
\hline Total & 2234 & $52.1 \%$ & $10(3-35)$ \\
\hline
\end{tabular}

appointments, with test results and clinical correspondence being the most frequently accessed functions. A study on the access requirements for patients attending a cystic fibrosis secondary care unit found that patients most valued their ability to access their clinical test results, appointment reminders, consultation summaries and medication details, and to communicate with their clinicians. ${ }^{23}$

\section{Implications of the study}

These findings suggest that older age, socioeconomic deprivation, being a non-English speaker and belonging to a non-white ethnic group are potential barriers to accessing a PHR in a hospital setting. These population groups tend to experience poorer health outcomes for many reasons. An integrative review highlighted the multiple health literacy demands posed by PHRs, which could result in the exclusion of people with disabilities and communication impairments. ${ }^{24}$ The unequal access to PHRs found in the current study poses the potential of PHRs to further widen health inequalities.

There was considerable variation in the uptake of myHealth@QEHB between clinical specialties. There are likely to be many factors influencing the sign-up of patients

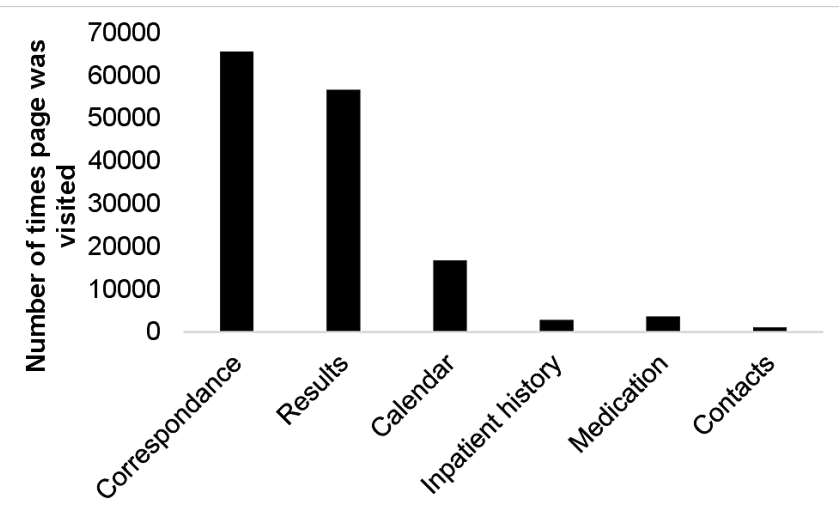

Figure 4 Number of times personal health record functions were accessed (all alive activated patients). to the PHR by clinicians, including the level of clinical engagement, organisational culture, and concerns about patient anxiety, security of the records and increased workload. ${ }^{25}{ }^{26} \mathrm{UHB}$ is moving to an open access sign-up process where patients will automatically be offered PHR access in outpatient clinics, thus bypassing the initial clinician-dependent sign up process. The impact of this on both the numbers signing up and activating their PHR and the characteristics of the patients who do so will need to be evaluated.

\section{Unanswered questions and future research}

Several barriers have been identified to PHR uptake by patients in the literature: technical difficulties including lack of access to the internet; difficulty understanding content including medical terminology, abbreviations and the meaning of test results; errors in information and lack of interest or usefulness. ${ }^{25}{ }^{26}$ While there are some suggestions of how to increase PHR use ${ }^{12}$ there has been little robust work on this area. Support with the initial logon has been associated with increased ongoing use ${ }^{17}$ and supported PHR drop-in sessions were used by the majority of users of a secondary mental health service. ${ }^{27}$ UHB are currently developing a myHealth@QEHB app for smartphones to increase accessibility. Further research is still needed to understand how this, and other approaches can be implemented to overcome the barriers and reduce inequalities in uptake and use of PHRs in different population subgroups. In addition, we did not use any theoretical models in the present study to evaluate myHealth@ QEHB. Future qualitative research could use models such as the Technology Acceptance Model to improve our understanding of the factors that may influence take up the technology. ${ }^{28}$ In the longer term, research is also needed on the impact of PHRs on the quality of clinical care, the self-management of chronic conditions and on clinical outcomes.

\section{Twitter Shamil Haroon @ShamilHaroon}

Acknowledgements The authors would like to acknowledge the contribution of the UHB informatics team in extracting the data for the study.

Contributors RC, SH, NB, KN and JF designed the study. RC and FM analysed the data. RC, SH, NB, KN, JF and NSW drafted the manuscript, and all the authors read, revised the manuscript, and approved its final version. KN and JF are responsible for the overall content as guarantors and accept full responsibility for the work and the conduct of the study, had access to the data, and controlled the decision to publish. The corresponding author attests that all listed authors meet authorship criteria and that no others meeting the criteria have been omitted, had full access to all the data in the study, and had final responsibility for the decision to submit for publication. KN and JF are joint last authors.

Funding The authors have not declared a specific grant for this research from any funding agency in the public, commercial or not-for-profit sectors.

Competing interests None declared.

Patient and public involvement Patients and/or the public were not involved in the design, or conduct, or reporting, or dissemination plans of this research.

Patient consent for publication Not applicable.

Provenance and peer review Not commissioned; externally peer reviewed.

Data availability statement Data are available on reasonable request. The anonymised participant data can be made accessible for further analysis or studies once approved by the clinical governance department at University Hospitals 
Birmingham NHS Foundation Trust. However, the data needs to be processed and analysed within the Trusted Research Environment (TRE), at the University Hospitals Birmingham NHS Foundation Trust.

Open access This is an open access article distributed in accordance with the Creative Commons Attribution Non Commercial (CC BY-NC 4.0) license, which permits others to distribute, remix, adapt, build upon this work non-commercially, and license their derivative works on different terms, provided the original work is properly cited, appropriate credit is given, any changes made indicated, and the use is non-commercial. See: http://creativecommons.org/licenses/by-nc/4.0/.

\section{ORCID iDs}

Shamil Haroon http://orcid.org/0000-0002-0096-1413

Nikita Simms-Williams http://orcid.org/0000-0002-4926-1995

\section{REFERENCES}

1 Tang PC, Ash JS, Bates DW, et al. Personal health records: definitions, benefits, and strategies for overcoming barriers to adoption. J Am Med Inform Assoc 2006;13:121-6.

2 NHS Digital. Guidance for developing personal health records. Available: https://digital.nhs.uk/services/personal-health-recordsadoption-service/personal-health-records-adoption-toolkit/guidancefor-developing-personal-health-records [Accessed 5 Mar 2019].

3 Armstrong S. Patient access to health records: striving for the Swedish ideal. BMJ 2017;357:j2069.

4 Australian Government, The Department of Health. My health record: national Opt-out. Available: http://www.health.gov.au/internet/main/ publishing.nsf/Content/my-health-record-national-opt-out [Accessed 5 Mar 2019].

5 Pohlmann S, Kunz A, Ose D, et al. Digitalizing health services by implementing a personal electronic health record in Germany: qualitative analysis of fundamental prerequisites from the perspective of selected experts. J Med Internet Res 2020;22:e15102.

6 NHS England. Empower the person: roadmap for digital health and care services. From the personalised health and care 2020 programme. Available: https://indd.adobe.com/view/ab41d569956d-4d45-a70a-940861e48f1b [Accessed 5 Mar 2019].

7 Scottish Government. Scotland's Digital Health and Care Strategy: enabling, connecting and empowering. Available: https://www.gov. scot/publications/scotlands-digital-health-care-strategy-enablingconnecting-empowering/ [Accessed 5 Mar 2019].

8 Welsh Government. A digital health and social care strategy for Wales. Available: https://gweddill.gov.wales/docs/dhss/publications/ 151215reporten.pdf [Accessed 5 Mar 2019].

9 Health and Social Care Board. eHealth and care strategy for Northern Ireland. Available: https://www.health-ni.gov.uk/sites/ default/files/publications/dhssps/interactive-ehealth-strategy.pdf [Accessed 5 Mar 2019].

10 NHS England. The NHS long term plan. Available: https://www. longtermplan.nhs.uk/online-version/chapter-5-digitally-enabledcare-will-go-mainstream-across-the-nhs/1-empowering-people/ [Accessed 5 Mar 2019].

11 Armstrong S. Hospitals that are leading the way to a digital future. BMJ 2017;356:j1366.

12 Wyatt J, Sathanandam S, Rastall P. Personal health record (PHR) landscape review: final report. The Royal College of physicians:
London 2016. Available: https://www.rcplondon.ac.uk/projects/ outputs/personal-health-record-phr-landscape-review [Accessed 5 Mar 2019].

13 Strobe. STROBE reporting guidelines for cross-sectional studies 2007. Available: https://www.strobe-statement.org/fileadmin/Strobe/ uploads/checklists/STROBE_checklist_v4_cross-sectional.pdf

14 University Hospitals Birmingham. Annual report and accounts 2017/18. University Hospitals Birmingham NHS Foundation Trust., 2018. Available: https://www.uhb.nhs.uk/Downloads/pdf/ AnnualReport17-18.pdf [Accessed 5 Mar 2019].

15 University Hospitals Birmingham NHS Foundation Trust. About us, 2019. Available: https://www.uhb.nhs.uk/about-us.htm [Accessed 5 Mar 2019].

16 Ministry of Housing, Communities and Local Government. National statistics: indices of multiple deprivation, 2015. Available: https:// www.gov.uk/government/statistics/english-indices-of-deprivation2015 [Accessed 5 Mar 2019].

17 Phelps RG, Taylor J, Simpson K, et al. Patients' continuing use of an online health record: a quantitative evaluation of 14,000 patient years of access data. J Med Internet Res 2014;16. doi:10.2196/jmir.3371. [Epub ahead of print: Available from].

18 Mold F, de Lusignan S, Sheikh A, et al. Patients' online access to their electronic health records and linked online services: a systematic review in primary care. Br J Gen Pract 2015;65:e141-51. doi:10.3399/bjgp15X683941

19 Goldzweig CL, Orshansky G, Paige NM, et al. Electronic patient portals: evidence on health outcomes, satisfaction, efficiency, and attitudes: a systematic review. Ann Intern Med 2013;159:677-87.

20 El-Toukhy S, Méndez A, Collins S, et al. Barriers to patient portal access and use: evidence from the health information national trends survey. J Am Board Fam Med 2020;33:953-68.

21 Turner K, Clary A, Hong Y-R, et al. Patient portal barriers and group differences: cross-sectional national survey study. J Med Internet Res 2020;22:e18870.

22 Perzynski AT, Roach MJ, Shick S, et al. Patient portals and broadband Internet inequality. J Am Med Inform Assoc 2017;24:927-32.

23 White H, Gillgrass L, Wood A, et al. Requirements and access needs of patients with chronic disease to their Hospital electronic health record: results of a cross-sectional questionnaire survey. BMJ Open 2016;6:e012257.

24 Hemsley B, Rollo M, Georgiou A, et al. The health literacy demands of electronic personal health records (e-PHRs): an integrative review to inform future inclusive research. Patient Educ Couns 2018;101:2-15. doi:10.1016/j.pec.2017.07.010

25 Jilka SR, Callahan R, Sevdalis N, et al. "Nothing About Me Without Me": An Interpretative Review of Patient Accessible Electronic Health Records. J Med Internet Res 2015;17:e161. doi:10.2196/jmir.4446

26 Larsen R, Brochot G, Lewis D. Study on personal data stores conducted at the Cambridge university judge business school. European Commission: digital single market 2015. Available: https:// ec.europa.eu/digital-single-market/en/news/study-personal-datastores-conducted-cambridge-university-judge-business-school [Accessed 5 Mar 2019].

27 Robotham D, Mayhew M, Rose D, et al. Electronic personal health records for people with severe mental illness; a feasibility study. BMC Psychiatry 2015;15:192. doi:10.1186/s12888-015-0558-y

28 Holden RJ, Karsh B-T. The technology acceptance model: its past and its future in health care. J Biomed Inform 2010;43:159-72. 